\title{
The Current Experience and Training of Romanian Occupational Health and Safety (OHS) Professionals
}

\author{
Cornelia Bohalteanu
}

Romanian Association for Safety and Health at Work, Romania

Copyright $\mathrm{C} 2016$ by authors, all rights reserved. Authors agree that this article remains permanently open access under the terms of the Creative Commons Attribution License 4.0 International License

\begin{abstract}
The study is about history of health and safety legislation in Romania, about European tools, empowerment procedures, organisations and association in the field. It's an overview about European tools to allow people free movements all around European Union (EU). The study presents tools which identifies the fundamental skills, the most important abilities and knowledge that people would need to be recognised, in order to allow free movements all around European employment market. The study is about possibilities to be voluntary recognised as a health and safety professionals across EU and why not, around the world. It's a brief list of ways of transfer and recognition of learning experiences in Europe, including vocational education and training, for a better understanding of qualifications from different EU countries. The research presents ENSHPO (The European Network of Safety \& Health Professional Organisations) and EUSAFE (European project) voluntary certification procedures for occupational health and safety

training needs of OHS practitioners, now that Romania has joined the EU in order to allow free movement of the work force. Knowing where to start and what needs to be improved, will allow the Romanian practitioners to be just as good and compete with their European colleagues. The study will show which of the Romanian empowerment procedures was better, with or without examinations and if this examination procedures make them better ones. The research is part of a study that aims to thoroughly analyze the transformation in the Occupational Health and Safety (OHS) field in Romania following the major political, economic, social and cultural transformations that are necessary in the context of Romania's accession to the European Union. The research evaluates the current experience and training needs of Romanian OHS professionals. A review of the changes in the legislation and qualification requirements in Romania will be presented and placed into the context of European legislation and standards.
\end{abstract} professionals (OHS) and where the Romanian practitioners are placed, if their qualifications could be recognised through Europe. The research presents the necessary characteristics for a well-developed profession, as mentioned by Ferguson \& Ramsay [1] and also presents IOSH, the most valuable health and safety professional association and the necessary steps for Romanian OHS practitioners to build a strong association. IOSH is the model of a profession and Romanian practitioners could learn to become Charted Members. The European Union single market - as well as the increasing number of companies operating across Europe that are applying a consistent set of safety and health standards to their work sites - has created a great need for safety and health managers with credentials that are recognised at a Pan-European level. The absence of a harmonised, agreed system for the mutual recognition of safety \& health qualifications at a European level creates uncertainty about professional competence across countries within Europe and may create problems for multinational companies in the effective use of their safety and health expertise. It also forms a barrier for safety and health professionals wishing to offer their services across the EU. Knowing their training level is necessary to determine the
Keywords Health and Safety, OHS Practitioners, Qualifications, OHS Competences, Training

\section{Introduction}

In the past 25 years, Romania has gone through major political, economic, social and cultural transformations, all necessary in the context of Romania's accession to the European Union in 2007. The admittance in the EU, the alignment of national legislation and OHS standardization across Europe, forces the profession to reach improvements to meet the European requirements for quality and competence; the question that arises and the project want to find out is: are the Romanian OHS professionals prepared?

This research is a small part from a bigger study whose aims is to thoroughly analyze the transformation in health and safety field and present the current experience and training needs of Romanian OHS professionals, to help professionals to obtain answers about their daily practices, that are best answered through systematic investigation, or 
the research process' DePoy \& Gitlin [2]. The purpose of the research is to understand the meanings, experiences of Romanian professionals through a naturalistic design, where the scope is exploration, understanding and description DePoy \& Gitlin [2]. The study is being undertaken by an insider, herself a practitioner, and therefore gains insights from experience but may be influenced by personal perception.

OHS professional is a relatively new profession in Romania, dating from 1998 and having many changes since then. Ferguson \& Ramsay [1] reviewed the characteristics of a well-developed profession and this research will evaluate training and career development, will discuss future steps that may be necessary.

The objectives of the study include:

1. To review the ways of becoming an OHS professional, through literature highlighting the legislative requirements and competences with the EUSAFE Project (2010-2012).

2. To evaluate the perception of Romanian OHS practitioners about the quality of their training and preference for delivering of future training (use survey);

3. To estimate the demand for development of a professional code of ethics for Romanian OHS professionals and to identify potential barriers (use survey);

4. To evaluate colleagues ' professional experience and training level, in order to establish the current training needs of the Romanian OHS professionals.

The project could be interesting for the OHS professionals from Romania, as the world is changing and practitioners must prepare themselves for the new challenges. The opening of labour market towards Europe could bring European OHS professionals to the country and this might create great competition for our experienced safety officers. The research will be interesting, also, for European OHS professionals, as they could find out who they are competing against in Romania and what the level of local competition is.

\subsection{Materials}

In the Romanian literature, there are no studies regarding the OHS professionals, their preparation level or the ways of becoming one; this is why the researcher used the legislative provisions and the mandatory steps needed to become an OHS professional as literature review. The researcher learnt from Robson [3] and proved that a research project could have three possible purposes traditionally recognized: to explore the background of how someone could become an OHS services provider, to describe the necessary steps and to explain one's development as a professional in the field. Due to lack of scientific evidence about this topic, the researcher could only hope that this project will be important for the development of OHS practitioners, considering that all research is concerned with contributing to knowledge Robson [3].

\subsubsection{History of Health and Safety Legislation in Romania}

The first evidence of activity related to labour protection in Romania can be considered to be the 1864 enactment of the Civil Code (inspired by Napoleon's Code) which established the legal basis of the individual labour contract. Chronology of labour protection activities as presented on the website of the Ministry of Labour is:

1890 - Servants Act

1894 - Regulation of unsanitary industries

1902 - Trades Act

1905 - Law on Child and Women Labour

1907 - Trade Unions Act

1912 - The first law of insurance in case of illness, accidents

1920 - Establishment of the Ministry of Labour

1927 - Setting up of Labour Inspection

1932 - Establishment of work and pension contributions

1945 - Trade Unions Act

1946 - Law setting up the work day and work departments in court premises

1949 - Law on Disease pension

1954 - Introduction of the work groups

1965 - Labour Protection Act No. 5 in force until 1996

1972 - Labour Code, Law No. 10 in force until 2003

1989 - The Romanian Revolution

1996 - Law No. 90 of labour protection (in force until 2006)

1998 - Order no.236 empowerment process of OSH specialists

2002 - Law no. 346 of insurance in case of accidents at work and occupational diseases

2002 - Order no. 251 changing the conditions regarding the empowerment of OHS specialists

2003 - Law no. 53 Labour Code (in force)

2004 - Order 167 changing the conditions regarding the empowerment of OHS specialists

2006 - Law no. 319 Occupational Health and Safety Act (in force) modified in 2010

2007 - Romania joined the European Union

\subsubsection{Steps for Empowerment of OHS Provider in Romania,} A History of Legislative Requirements

The economic development of Romania has increased the attention given to work and everything related to the process. The history of health and safety is tightly connected to the qualification necessary to workers for facing the novelties brought over by work technologies. The induction and training of employees was accompanied by the concern to provide decent work conditions and to enforce some measures to protect the components of the work system.

Order no.236/12.05.1998 established, for the first time, the OHS external services 'provider empowerment and the requirements for OHS consultant. The mandatory conditions for the authorization to provide services in the field of OHS, 
are:

- (art. no 4) 5 years of experience in the field for those with university degrees, or 15 years for those with pre university qualifications; for the members of Labour of Ministry or local inspectorate, 4 years of experience are enough;

- (art. no.6 point d) Technical university degrees and post university degrees with a duration of at least 6 weeks in the work protection field;

The subscription folder should contain (according to art.no.6): the mandatory request form, Curriculum Vitae, diplomas and certificates from the work protection courses, the proof for the years of experience in the work protection field and also in the economical domain of activity, for the empowerment authorization request (art.no.16 point d).

The authorization procedure (art.no.9) included presenting a file with all the documents, passing a written exam and interview with representatives of the Labour Ministry. The validity of the certificate so obtained, was of 3 years (art.no.11); for renewing the certificate, a new examination was done after 3 years, with the specification that continuous professional development courses (CPD) had to be attended in the meantime.

Order no. 251/01.07.2002 followed; it reduced the years of experience from 15 to 10 (art.no.14), for those with pre university qualifications and increased post university courses (art.no.4) from 6 to 8 weeks.

Order no. 167/16.04.2004 added new conditions, such as a recommendation from the Local Labour Inspectorate (art. no. 24 point $b$ ), with mandatory examination by members of Labour Ministry or local Inspectorates (art.no.24 point b).

Law no.319/26.07.2006 and the Government Decision no. $1425 / 30.10 .2006$ changed matters in the field. The procedure was changed, the authorization (art.no.36) being made only after the analysis of a candidate's file by a board of professionals from the local Inspectorate. Other changes were made: the name was modified from work protection, to external services for occupational health and safety (art.no.28) and also the minimum requirements for the employees and the leader of this external services (art.no.32 (1) and (2)). The empowerment was made now for a minimum of 5 years' experience, without the mandatory requirement of having experience in any economical field of activity (art.no.37 point e); also, a declaration of confidentiality became mandatory (art.no.37 point i). Art.no. 45 also stipulated a year for re authorization of all those empowered by the former legislation (Law no.90/1996), following to be done by a board of professionals from the local Inspectorate, named by Order no.754/16.10.2006. The validity of the certificate so obtained was of 3 years (art.no.41) - followed by a new examination of submitted files by the local inspectorate (art.no.36); also, health and safety courses needed to be attended (art.no.42) in those 3 years.
Two levels of training were introduced (art.51):

- OHS technician (art.no.48) - with technical high school degree and health and safety courses of at least 80 hours;

- OHS expert (art.no. 50 )- with an engineering degree, health and safety courses of at least 80 hours and also post graduate courses of 180 hours;

The modifications brought by Government's Decision no. $955 / 2010$ had the purpose of harmonizing the Romanian Legislation with the European Directive 2005/36/EC, in order to allow the free movement of OHS professionals within the European Union, Romania being a member since 2007. These modifications (art no.45 (1), 45 (2), 45(3), said that any OHS professionals authorized in a similar way in any of the EU member states could practice in Romania, just by notifying the Empowerment Commission.

For empowerment, there was no longer the requirement to prove experience in some economical area of activity (art.no.37point.g), but 5 years' experience in the field of health and safety, to become the leader of the external service; the conditions referring to mandatory CPD (art.no.42) courses and the limited validity of the certificates (art.no.41) were dropped. All these changes brought a large number of new OHS practitioners on the market.

For those OHS professionals authorized in a similar way in their own countries, there is a possibility of them practicing in Romania, if they were authorized in the same conditions as the local practitioners (art no 45(2)). These empowerment conditions require the submission of a file with the evidence papers to The Empowerment Commission from the local Labour Inspectorate (named by Order no. 455/14.06.2010), without any examination.

The research is also a history of health and safety legislation in Romania, about European tools, empowerment procedures, organisations and association in the field. It is an overview about European tools to allow people free movements all around European Union (EU). The study presents tools which identifies the fundamental skills, the most important abilities and knowledge that people would need to be recognised, in order to allow free movements all around European employment market. The study is about possibilities to be voluntary recognised as a health and safety professionals across EU and why not, around the world. It's a brief list of ways of transfer and recognition of learning experiences in Europe, including vocational education and training, for a better understanding of qualifications from different EU countries.

The research presents the necessary characteristics for a well-developed profession, as mentioned by Ferguson \& Ramsay [1] and also presents IOSH, the most valuable health and safety professional association and the necessary steps for Romanian OHS practitioners to build such a strong association. IOSH it's the model of a profession and Romanian practitioners could learn to become Charted Members. 


\subsection{Methods}

Questionnaires have been chosen for the research since it is important to be objective, while reflecting the values, perceptions and interests of the respondent Gray [4]. Questionnaires, by their very nature, can start to impose a structure on the answers and shape the nature of responses in a way that reflects the researcher's thinking, rather than the respondent's Denscombe [5] ; in order to avoid this limitation, the researcher used open questions for giving her colleagues enough freedom to express themselves. It is quite difficult to develop questionnaires that are valid, reliable and objective. Validity means that an instrument must measure what was intended to measure, Gray [4], in this research, the current experience and training needs of Romanian OHS practitioners. The research has to be very precise if the study wants to prove its external validity - the extent to which findings from a study can be generalization as Gray [4] suggests.

A number of key attributes of a good questionnaire, Denscombe [5] were incorporated into the design in order to ensure that:

- Privacy was assured in this case the respondents ' names are known only by the researcher; every questionnaire is identified by a number.

- The respondent will have some knowledge on the topic - the respondents are participants because they have an active role - they are OHS professionals.

- The proposed style of questions is suited to the target group - the target group consisted of OHS practitioners, members of ARSSM (Romanian Health and Safety Association).

The participants have to answer 18 questions about their age, gender, years of experience in OHS domain, education and training, the year of their authorization by Labour Ministry as OHS practitioners, training needs, voluntary empowerment procedures, their opinion about code of ethics, ways of granting CPD. Ethical dilemmas around access, who and how are accessed, the fact that researcher must continually reflect around the data collected, Miller \& Bell [6] and about their representativeness for OHS professionals, was resolved by working with and for a professional association. ARSSM's voluntary members understood the necessity of the study and they freely agreed to participate by signing the consent form and filling in the questionnaires.

Other reasons for choosing questionnaires in this study, because they are economical, low cost in terms of materials, money and time; they supply standardized answers, all respondents are asked exactly the same questions; they have a wide coverage; they contain pre-coded data and they eliminate the effect of personal interaction with the researcher, Denscombe [5]. For this particular research, it was relatively easy to contact and arrange the participation of the respondents, because the questionnaires were filled in during the general meeting of ARSSM and the researcher had the opportunity to explain to the participants why the study was of high importance and all the steps for being part of the survey.

Some disadvantages of using the questionnaires were anticipated at the designing stage. The questions were limited in length to four or six pages, to avoid the return rate being adversely affected or respondents give flippant, inaccurate or misleading answers, Gray [4]. Another important potential limitation is the fact that attention is focused on topic that the researcher considers meaningful or important. The respondent has no freedom to negotiate the relevance of the attribution with the researcher, Cassel \& Symon [7]. Incorporation of open questions gave them the opportunity to express their own ideas about the topics.

\section{Results and Discussion}

The results of the research depict an image of Romanian OHS practitioners with their education and experience, wishes for improving the personal skills, outlining the portrait of a profession. The participant practitioners represent just a small part of all the OHS practitioners in the country out of a total of three thousands, Inspectia Muncii, HSE [8] but they are representative for Romania, being members of a nationwide professional association, ARSSM. Being member of a professional body, represents one of the steps for becoming a true professional, Ferguson \& Ramsay [1] as this experience brings together voluntary members from all important cities of the country for learning from each other and sharing knowledge. This is an achievement as they are likely to be more reflective and evaluative about their profession. On the other hand this may introduce some achievements in place, as discussed above.

The image of the Romanian OHS professionals can be seen in the results from the first nine questions. The age of the participants shows that the ones more interested in this research are of more than 50 years old (question no.1), a few of which are women (question no.2), with about 20 years of experience in health and safety (question no.3), many of them have a university degree (question no.4) and plenty of OHS courses (question no.5), a third of them are in this field before 1996 prior to Law no.90/1996 (question no.7), a third of them are full time OHS practitioners and more than a half have their own consultancy company (question no.6). Statistically $55,7 \%$ from Romanian population, Ziarul Gandul (The Thought Paper) [9] are mature person (25-64 years) and this demographic result can be seen here as a sample of mature person having a profession. The high percentage is more than 50 years old category in this research, maybe as a result of empowerment conditions and necessary years of experience or maybe because of the lack of interest of young professionals about being member of a professional association like this.

Statistically in Romania there are $51 \%$ women from the people, but as OHS participants in the research are $80 \%$ men, maybe OHS is seen as a male profession and is not likely to reflect the true gender balance of the wider population. 
There are 12 people with 10-20 years of experience in the field and this experience could reflect their age group, around 30-50 years old (q. no.1b), 1c)) and 7 people with more than 20 years' experience among that one with more than 50 years age (q.no.1d)).

Years worked in a regulatory body it's a particular way of becoming OHS practitioners and reflect the situation of members of Local Inspectorates who didn't have to have health and safety courses to became OHS practitioners; the legislation allowed the labour inspectors to be empowered as safety practitioners, without any exam, just through the submission of a file. There are 7 members of local inspectorates with more than 10 years' experience in health and safety; one of them could be of the five empowered as OHS professionals before 1998, if we look at question no.7.

About participants education's, there are 25 people university graduate because having one was mandatory for doing post university studies (courses) with a length of 180 hours in health and safety. Former members of local inspectorate were mandatory of having university studies for being an inspector, so all HSE practitioners have a high level of training.

All of the participants have lots of health and safety courses but which one was more useful for their training will be seen in the answers from questions no.10 and 11. Having such an experience in doing OHS courses will help the researcher to rate which ones are more useful for their training needs.

There are 8 participants with HSE master degree and one doctor. If extrapolated to the wider population of OHS practitioners, we can state that maybe, a third of them are highly educated. There are 25 from a total of 29 people university graduate because having one was mandatory for doing post university studies (courses) with a length of 180 hours in health and safety. Former members of local inspectorate were mandatory of having university studies for being an inspector, so all HSE practitioners have a high level of training. Seven of them graduate a second university and this is a good reason for stating they are educated.

The Romanian OHS professional is also interested in continual professional development (CPD) and question no. 13 proved this interest. If we are looking ways of granting credits and utility of selected ways for CPD we can check question no.14. These results could be the starting point for organizing CPD for OHS professionals in a different way than just doing another course.

All the 27 participants who answered question no.14 agreed the granting credits system by participating to conferences and workshops, as a way of accumulating knowledge and credits simultaneously. We could allege that the wider population of OHS practitioners is interested and very happy about $\mathrm{CPD}$, about learning from others through workshops and conferences.

It was a time when attending courses was mandatory for CPD, but these days practitioners proved they have other wishes for improving their skills, knowledge and expertise.
This represents a good way for ARSSM and other similar organisations for developing and growing the number of members or finding other people interested of becoming member of a professional association by organizing conferences, workshops and OHS meeting each other's. There are a few comments who illustrate their position about this subject: 'It's Romania's obligation as a EU member"; "They (EU) required so we can meet those special requirements of foreign employers", "Very useful because they permanently refresh the know-how with new methods in the area of activity".

The answers to question no.14 (figure .1) looks at the various ways of training that could be delivered and asks participants to indicate the types of subject that they would like to attend. CPD could be achieved through inclusion in one or more of the options below and they indicated most important subject to study. These results shows that Romanian OHS practitioners are interested in CPD and have clear ideas about what would be needed for developing their knowledge and agreed granting credits for participation in conferences and workshops. There were given 14 tips of granting CPD and the participants are very clear about their wishes, the most voted ( 24 answers with 8 would attend and 15 certainly attend) was interactive workshops on a theme previously released before the meeting and discussed over several hours 14b). Some of them have even propositions about theme, like alternative method of risk assessment, organisation and ways of working of H\&S internal services, collective protection for workplaces, quality of $\mathrm{H} \& \mathrm{~S}$ providers. The participants are very interested about analysis of work accidents with (14i) human casualties and deceased ( 5 people would attend and 17 certainly attend), even if MOK trials are almost unknown in Romania. They consider this analysis a good opportunity in motivating staff to increase attention given to health and safety at work and they wish to learn new methods of determining the causes and consequences of work accidents. We can put here together the answers given to $14 \mathrm{~h}$ ) meetings with prosecutors or judges to present the steps of a process in criminal and/or civil practice related to work accidents ( 7 people would attend and 14 certainly attend) for proving their interest about the circuits of documents between involved organisations, tracking and social implications of a serious work accident. This result is a strong proof that people wants MOK trials even a few of them known that powerful organization like IOSH [10] organize such.

Meetings with experts to answer questions regarding law enforcement (9 people would attend and 12 certainly attend), the impact of legal regulations on health and safety, meetings with members of Executive Health and Safety all over the country have 23 answers.

Case studies to analyze legal requirements neglected 14e) is another new way of learning in Romania, but the participants shows their interest about with 8 "would attend" and 10 "certainly attend" and they have interest about employers liability in health and safety. 




- 1 - would never attend

- 2 - might attend

14a) One day short course

14b) Interactive workshops

14c) Classical teaching in a school setting

14d) Discussion on legislative news to deepen understanding

14e) Case studies to analyze legal requirements

14f) Meetings with preset agenda to include the presentation of the work followed by analysis of a real case

$14 \mathrm{~g}$ ) Meet with experts to answer questions regarding law enforcement

14h) Meeting with prosecutorsor judges to present the steps of a process in criminal and/or civil judicial practice

14i) Analysis of work accidents with a human victim

14j) Seminars for analyzing disasters related to negligence at work

$14 \mathrm{k})$ Others

Figure 1. Methods of obtaining continual professional development, CPD

\section{Conclusions}

The OHS profession was born in 1998, so it is a relatively new in Romania, therefore, so far, no studies have been made about the professional's level of knowledge and their needs. As outlined above in the study if we discuss how to become real professional practitioners, ready to fight with our competing peers from the EU, we need a lot of studies about what the current preparation level is, what their training needs are, if any certification is needed.

The participants are very interested in certification by an international organization like ENSHPO - knowing that ARSSM is an ENSHPO member and they agree with Ferguson \& Ramsay [1] that certification is viewed as credible evidence of skill and knowledge within a field of professional practice.

ENSHPO believes there is a need for a voluntary standard for Occupational Safety and Health Managers (EurOSHM), which is accepted throughout the European Union. The EurOSHM standard meets that requirement. Furthermore ENSHPO has developed a second standard to reflect the level of competence required for those with a health and safety role either reporting to managers or working in lower risk industries as Occupational Safety and Health Technicians (EurOSHT). ENSHPO decided to introduce these voluntary standards for EurOSHM and EurOSHT, together with a process for assessing and recognising both national certification systems for these two levels of qualification and national schemes to assess individuals against these ENSHPO criteria" ENSHPO [11].

Minimum requirements and criteria for eligibility of individuals for EurOSHM are:

- a university degree at least at Bachelor level

- occupational safety and health training courses at a professional level, at least 250 study hours with a balanced coverage of the topics and with 150 hours examined

- professional work experience for at least two years full-time since the completion of the occupational safety and health training

- continuous professional development (CPD)

The candidate shall be a full member of an ENSHPO national professional organisation or association. Renewal of the certification at three yearly intervals. The ENSHPO Certification Standard is voluntary. The candidate, by 
submitting the application form agrees to ENSHPO Certification Standard provisions and unconditionally accepts its rules and procedures, the ENSHPO Code of Conduct and the resulting duties and obligations.

Among the necessary characteristics for a well-developed profession, as mentioned by Ferguson \& Ramsay [1] should be:

- A valuable service to society and Code of Ethics, the study shows their work is about learning others working safely and the second one is now missing. The Romanian OHS practitioners are aware about the necessity of a voluntary code of ethics and they express very clearly their support for developing and implementing of such a code.

- a specialized body of skills and knowledge, the Romanian law requests health and safety courses, minimum years of experience, as seen in the empowerment procedure and all these can be the proof for their skills.

They also should have:

- Academic qualifications, the study shows that many of them have one or two university degrees not at least Bachelor degrees.

- CPD could be a challenge because it's not mandatory at the moment and isn't officially recognised as a way of learning.

But all interviewed practitioners supported as a way of learning and agreed that is extremely useful.

This research cannot yet declare the OHS practitioners' profession as being a well-developed one in Romania, looking (only) at the results of this research. The future necessary steps are known, as it has been suggested by Ferguson \& Ramsay [1]:

The existence of an accrediting organization - could be ARSSM using ENSHPO or EUSAFE empowerment procedures. OHS practitioners were very interested about ENSHPO system of certification, they supported the idea of being recognised by an international organisation and many of them are fulfilling the requirements. The study shows that it is the proper time for this certification procedure, the practitioners desire such an empowerment procedure they have opportunity and evidence for being recognised as European OHS practitioners.

Establishes conditions for access (establishing a metric(s) that can discern the qualified from the unqualified) - steps for becoming an ARSSM [12] member used these days should be carefully revised, qualifications exists but are not mandatory. Future development might grow towards chartered status, where membership of a chartered organisation is required in order to practice. This system already exists in Romania for doctors, accountants, engineers and if we are looking for European models, we can fallow IOSH [10] system of chartered safety and health practitioners.

Establishes the professional associations with their roles: socialization/ collegiality; offering CPD training courses; lobbying for specific policy and legislation that affect the practice of the profession. Knowing, as an insider, the way of working of an association like ARSSM, the researcher thinks that there is a lot more work to do in order to grow and achieve the expectations of a mature, well-established association;

Establishes and enforces a professional code of ethics as a common characteristic of a profession. A proper and suitable way needs to be found, as the questioned members express their wish for having a code of ethics and they showed very clear that the proper time is now.

To the 7th International Conference Workingonsafety.net [13] 30 September - 03 October 2014 Scotland, UK which I attended, it was a technical session,TS10, Competence Workshop, chaired by Jane White - IOSH, UK. In this session the speakers, Andrew Hale former chairman of Certification Committee of ENSHPO, Pam Pryor - Registrar of Australian OHS Education Accreditation Board, Australia and Luise Vassie, Executive Director- Policy, IOSH, UK have had some presentations about developing a global framework for the training and certification needs across the world. Speakers and participants have underlined the necessity of an international harmonisation of qualifications for the occupational health and safety practitioners and their presentations are the proof that OHS professionals from all around the world are interested to be international recognized. The common empowerment procedure should be acknowledged and encouraged by all OHS professionals and now days ENSHPO and INSHPO (International Network of Safety and Health Practitioners Organisations) [14] are working together to a common framework.

Future licensing of OHS professionals may rely on ENSHPO or EUSAFE or INSHPO competency schemes; one question arises: which is the best way to equate the years of professional experience with theoretical education (diplomas, certificates). Transforming professionals experience gained with or without studies, diplomas, recognized skills in the vocational training system and the ways to do so, represent a point of interest for the Romanian OHS practitioners and the research will present their opinions.

This research wants to be a starting point for all OHS practitioners knowledge about themselves; it is time for all of us to be aware of the right moment of becoming a certified OHS professional, for proving that our level of skills and knowledge is similar with the EU standards.

Romania as EU member should use the European tools:

- EQAVET and EQF are ways of recognizing the vocational learning all over the EU and could be used by Romanian OHS practitioners with the support of Labour Ministry, Education Ministry and professional associations;

- ECVET a system to help the transfer and recognition of learning experiences including vocational education and training (VET) for those wishing to use this instrument in EU. 
- ECTS credit points; for example now, a university diploma has 240 credits. A student should study 25-30 hours for a credit, about 1500-1800 hours of work for an academic year and 7200 hours for a university diploma.

\section{Acknowledgements}

The researcher would like to thank to academic advisors and consultants professors Dr. Alan Page and Dr. John Watt, to module leaders professors Hemda Garelick and Dr. Gordon Weller from Middlesex University London, UK for their support and cooperation.

The project was carried out by Middlesex University London, initiated and accompanied by ARSSM Romania.

\section{REFERENCES}

[1] Ferguson, L.H., \& Ramsay, J.D., (2010) Development of a profession, The Role of Education \& Certification in Occupational Safety Becoming a Profession, In Professional Safety. Journal of the American Society of safety engineers. October 20, 2010, 24-30, retrieved September 15, 2013 from: http://www.asse.org/professionalsafety/indexes/2010.php.

[2] DePoy, E., \& Gitlin, L., Introduction to Research. Multiple Strategies for Health and Human Services. Printed: United States of America, Mosby-Year Book, Inc., 1994.

[3] Robson, C., Real World Research, Wiley and Sons, Ltd, Publications, London, 2011.

[4] Gray, D., Doing research in the real world, Sage Publications Ltd., London, 2004.

[5] Denscombe, M., The Good Research Guide, 2nd edn., Berkshire, England, Open University Press, 2003.
[6] Miller, T., \& Bell, L., Consenting to what? Issues of access, gate-keeping and 'informed' consent, London, Sage Publications Ltd., 2002.

[7] Cassell, C., \& Symon, G., Essential Guide to Qualitative Methods in Organizational Research, London, Sage Publications Ltd., 2004.

[8] Online Available http://www.inspectmun.ro/site/Servicii\%20 externe/Actualizare $\% 20$ Lista $\% 20$ servicii $\% 20$ externe $\% 20 \mathrm{abi}$ litate_13_08/Lista_serv_2012. Inspectia Muncii.Lista servicii externe. Online available from http://www.inspectmun.ro/sit e/Servicii\%20externe/Actualizare\%20Lista\%20servicii\%20e xterne\%20abilitate_13_08/Lista_serv_2012.

[9] Online Availablehttp://www.gandul.info/financiar/recensama nt-date-finale-cati-romani-mai-sunt-in-romania-hartapdf. Gandul Paper (The Thought Paper). Recensamant (Census). Gandul Paper. Online available from http://www.gandul.inf $\mathrm{o} /$ financiar/recensamant-date-finale-cati-romani-mai-sunt-inromania-hartapdf.

[10] Online Availablehttp://www.iosh.co.uk/Membership/Aboutmembership/Professional-development/About-CPD.aspxpdf. IOSH. Membership. Online available fromhttp://www.iosh.c o.uk/Membership/About-membership/Professional-develop ment/About-CPD.aspxpdf.

[11] Online Available http://www.eusafe.org/index.php/en/theprjeng.html.pdf. EUSAFE. Online available from www.eusafe.org, http://www.eusafe.org/index.php/en/theprjeng.html.pdf.

[12] Online Available from http://www.arssm.ARSSM.Online available from http://www.arssm.

[13] IOSH (Institute of Occupational Safety and Health), Working On Safety, International Conference. 'Technical sessions 10.Competence workshop', Learning from the past to shape a safer future. Scotland, UK, 30 September-03 October, Leicester UK, IOSH, pp.88-93.

[14] Online Available from http://www.inshpo. INSHPO. Online available from http://inshpo.org/about.php. 